\title{
Julian Meyrick
}

\section{Reflections on the applicability of case study methodology to performance as research}

\begin{abstract}
Over the last two decades, practice-led research (PLR) has rapidly expanded in the Australian university system. This paper lays out the potential exegetical benefits of one methodology, the case study, for one disciplinary area, Performance as Research (PAR). The epistemological issues currently besetting PAR are identified and a brief account of the debate in the 1990s given. The values and concepts of case study methodology as these relate to the Chicago School of sociology are then described. The point is made that identifying an artwork as a 'case' means viewing it not (only) as a unique experience, but as representative of a certain kind of problem. This allows it to be placed in a comparative vista, either diachronic or synchronic. Case study methodology's 'emic' sensitivities are mentioned in relation to evidentiary procedures ie. how subjective experiences can validate general claims. The paper concludes with a brief example of how the approach can be applied to one potential project, As We Forgive by Tom Holloway, a play I directed for the 10 Days on the Island Festival in 2013.

Keywords: practice-led research, performance as research, case study methodology
\end{abstract}

\section{Introduction}

In a review of Practice-led Research, Research-led Practice in the Creative Arts (Smith \& Dean 2009), Dominique Hecq and Robert Banagan note the 'chasm that regrettably remains between the artist as practitioner and the [pedagogical] institution [of academia itself]', and that 'despite alternative modes of production and concomitant potential for methodological, procedural and even political change, the status of knowledge and knowledge production in the creative arts remains a vexed topic' (Hecq \& Banagan 2010). It is sixteen years since Dennis Strand presented his report on creative work outputs and their prospective research weightings in university assessment indices (Strand 1998). In the section focusing on live performance he defines 'performance as research' (PAR) as occurring when:

a production becomes an intervention in an established scholarly debate, dialogue or discourse, OR when it initiates or seeks to initiate such as debate. Any performance-as-research project must make explicit its relationship with that debate and communicate the ways in which the terms of the debate have been changed by the research project. (Strand 1997: 89) 
Since the 1990s there has been considerable growth of the practice-led research area (PLR) within the Australian tertiary education system, and a finessing of its definitions. But the basic ingredients of PAR - live performance on the one hand, scholarly debate on the other - remain the same. This paper is a reflection on that conjunction of forces. It is concerned with knowledge claims and how these apply to performance work that as performance work is driven by non-scholarly norms and values. The relationship between validity in an academic sense and excellence in an aesthetic one is obviously a problem for PLR [1]. Estelle Barrett and Barbara Bolt list the epistemological features of the area, its situated-ness, its experiential nature, its use of emergent processes, its interdisciplinarity; but they admit 'there is a need to generate appropriate discourses to convince assessors and policy-makers that within the context of studio-based research, innovation is derived from methods that cannot always be pre-determined and 'outcomes' of artistic research are necessarily unpredictable' (Barrett \& Bolt 2007: 3, emphasis in original). In laying out six conditions for PLR, Brad Haseman and Daniel Mafe argue that:

the central problem is one of research methodology. Traditional research methodologies ... are characterised by well-established and widely shared procedures and protocols... For artists and creative practitioners seeking to join the community of researchers this environment can seem unsympathetic and dismissive of their contribution. (Haseman \& Mafe 2009: 211-12)

There is a job to be done, then, not so much theoretically justifying the knowledge-claims PLR generates, but supplying robust methods to shape individual projects and provide points of recognition for traditional scholarship. These methodologies can be emergent but not infinitely divergent, lest the area fail to stabilise. 'Finding methods for artists to examine their own practice has the potential to open vast new avenues of knowledge,' Hecq and Banagan observe. '[But] the description of practitioners' methods, engaging consistent methodologies in some form, and developing a common vocabulary appear to be and remain the sticking points' (Hecq \& Banagan 2010).

This paper argues for the benefits of one methodology in particular, the case study. This is a qualitative research approach and takes its place alongside related methods such as grounded-theory, ethnography, action-research, symbolic interactionism, ethnomethodology and so on. Haseman has discussed the application of qualitative approaches to practice-led research, most notably in his 'Manifesto for Performative Research' where he proposes an entirely new paradigm for PLR scholarship (Haseman 2006). It is a bold move to declare a new mode of research before the existing methodologies attached to the area have attracted broad consensus; bolder yet when, as all admit, these involve subjective valuations that militate against the formation of that consensus. As a practicing director frequently involved in the development of innovative performance projects I have no problem accepting a priori their potential as investigative vehicles. Like most artists, however, I have trouble explaining their distribution of interrogative pressure in a way that is exact and generalisable. How are good productions in an artistic sense valid in a research one? Can a bad production be valid? Can a good one be invalid? Who judges the intersection of these values? In 1997 Rod Wissler noted that, 'assessment in the performing arts is a vexed issue. Whether it's the morning after newspaper review, the undergraduate intake audition or end of semester presentation, the funding body performance report or the eisteddfod adjudication, nobody seems to be able to get it right' (Wissler 1998: 59). The matter of artistic excellence is, historically speaking, deeply controversial and one inseparable from issues of art form definition. Haseman and Mafe talk 
about 'identifying and engaging with the 'professional' frames within which practice is pursued' and that 'often these arbiters of the professional are conservative in nature and research must find ways of influencing these ... dictates' (Haseman \& Mafe 2009: 216). Professional practice supplies terms of judgement for creative work either by imposing its standards on artists or provoking a reaction against them. It is a powerful institutional formation with which the Academy must treat if it wishes PAR to have positive relations with the field. Two solutions to the assessment of artistic excellence suggest themselves. First, a trait-based measurement model, counting impacts; second, a bank of specialised assessors judging what Alison Richards calls 'knowledgein-action' (Richards \& Prior 1997: 56). But the first tends to replicate the norms of the field, while the second suggests a zone of judgement above the ructions that regularly up-end it. In truth, assessment of artistic excellence in PLR is likely to remain contentious. Live performance is a collective, resourceintensive endeavour - and an ephemeral one. However voluminous ex post facto documentation, once it's over, it's over, and the opportunities to revise authoritative judgements are minimal.

The case study is not a new instrument of qualitative research. In fact, it is one of the oldest of its associated methodologies. As such it has been the target of considerable philosophical reflection, and has developed a rich and varied literature. Methodologies are more than an array of processual strings linking concepts to empirical referents. They have a life of their own, specific histories, current agendas, given sympathies. They are repositories of values, including reflexive values, not an inert 'box of tools', as one ubiquitous but unhelpful metaphor has it. As the brief summary below hopefully shows, the case study is a flexible approach, able to extract from the singular experiences of the phenomenal field, research objects that are plausible, comparable, and about which valid conclusions can be drawn. In prosecuting its scholarly aims it is considerate of that field and disinclined to over-trump embedded practices and their associated terms with its own supposedly superior categories and interpretive devices. Usefully, it has a long history of defending its phenomenal sensitivity against attacks from erstwhile more 'systematic' quantitative approaches [2]. It can therefore supply PAR not only with a methodology but a congery of values that are 'edifying' in Richard Rorty's sense of that term [3]. Above all, it is pragmatic in its approach to issues of artistic excellence, seeing these as a dimension of the field to be respected without being replicated. In return, it makes a few basic demands of all research claiming that title, ones that are: i. straight forward; ii. compelling; and iii. inclusive. Of the fragility of PLR Hecq and Banagan comment, 'one has to wonder how long the guillotine of funding, resources and integration into the institution will wait' (2010). This paper does not argue that the case study is a magic bullet solution for the methodological issues facing the area. It argues that, as a well-established research approach it offers an epistemological framework allowing PAR room to grow convincing examples of best practice.

My own involvement with PAR dates from the 1990s. At this time, discussion took the form of a contrast between, on the one hand, 'pure' performance as research and, on the other, 'research equivalent' creative arts activity (Gillies 1997). The difference between the two was the presence of the 'research question', the sine qua non of academic inquiry, assumed to play out both in the operation of PAR and its outcomes. 'Conservative', 'pragmatic' and 'liberal' interpretations of the area vied for consideration, while terms subdivided in an attempt to nuance positions being occupied (thus, practicebased research, practice as research, performance research and the current front-runner, practice-led research.) My interest followed in the wake of the Strand Report, and its attempt to find a yardstick 1.0 publication rating for creative activity (Strand 1997: 90-1). I was sceptical of arguments for a 
national peer assessor body as the best means of rating projects by way of ' $\mathrm{a}$ model of iterative evaluation based on the interplay of aesthetic and analytical responses' (Wissler 1998: 60). Accordingly, I advised my own university, La Trobe, to adopt a 'liberal' approach to the awarding of research equivalents and a 'conservative' one to PAR. This led to the development of the so-called JForm, which thereafter assumed a life of its own as a means of weighting performing arts activity within the University system [4]. Between 1999 and 2002, I was involved as a creator and researcher in an ARC-funded PAR project [5]. This experience confirmed my feeling that notions of artistic excellence and questions of research validity were congruent but not homologous, and I envisioned a defining bivocality to PAR, a lively jumping between two orientations, rather than an attempt to synthesize them into one matrix of value. I thought what was going on was an institutional confluence more than an epistemological realignment. I was not cynical, just knowledgeable about the different contexts in which the creation of art - the proceeding from nothing to something - and the critical analysis of it - the proceeding from something to something else - takes place. As someone who has now spent twenty years flitting from one set of institutional expectations to another, not always easily, this is still my position. So is the marriage between the two areas destined to always be one of convenience?

\section{The Case Study and the Chicago School}

The case-study approach arises from the verstehen sociology associated with Wilhelm Dilthey, Georg Simmel, Max Weber and the so-called Chicago School. It is hermeneutically inclined and usually, but not always, antipositivist in demeanour. It is not in the business of promulgating le Comtestyle 'social laws', though it is certainly interested in structural causes. In a word that has no exact equivalent in English it utilizes Geisteswissenschaften or 'the understanding method', one that is usually contrasted with positivist sociology's deterministic approach, taken from the physical sciences. he contest between these intellectual positions has two waves, one in the nineteenth century, and one in the twentieth century, when positivism caught its second wind. Carl Gustav Hempel's paper The Function of General Laws in History in 1942 is regarded as a high water mark of this revival, with Hempel arguing for a deductive model of human action from which subsuming covering laws could be derived. In retrospect, there is something bleakly humorous about such a theory appearing when the world was exploding into unprecedented destruction and chaos and the reaction against positivism should not be seen solely in scholarly terms. The case study has as part of its deep motivation a desire to produce accounts adequate to reality and not simplified versions of it that have little empirical purchase. Peter Winch's The Idea of a Social Science published in 1958 encapsulates the verstehen point of view as it stood on the cusp of its own reassertion:

[The researcher] must understand the 'meaning' of the behavioural data which he registers in order to turn them into social facts. He achieves this understanding by describing (interpreting) the data in terms of the concepts and rules which determine the 'social reality' of the agents whom he studies. The description, and explanation, of social behaviour must employ the same conceptual framework as the social agents themselves. For this reason the [researcher] cannot remain an outsider in relation to his object of study in the same sense in which a natural scientist can. This is the core of conceptual truth, one could say, in the psychologistic doctrine of 
'empathy'. Empathic understanding is not a feeling; it is an ability to participate in a form of life. (Winch cited in Von Wright 1971:29)

From its beginnings in the 1890 s, Chicago School sociology was the recipient of verstehen values and developed a distinctive application of them, participant-observation (Lutters \& Ackerman 1996, Deegan 2001). Not all participant-observation is concerned with case studies, nor are all case studies derived from participant-observation. But clearly they are linked because empathy as an epistemological tool (as opposed to a moral good) requires proximity to its referent to derive a ground for investigation. The Chicago School also had two peaks, one under William Thomas, Robert Park and Ernest Burgess, seeding a string of urban ethnographies in the 1920s and 1930s, another after World War 2 associated with Erving Goffman and Howard Becker. Becker has been a theoretical exponent of case study methodology (Becker 2009) and a sometime historian of the Chicago School tradition (Becker 2011). The literature around the case study is sophisticated (Hamel 1993, Yin 1989, Stake 2005). It is not a prescriptive set of rules, but a style of research allowing for a number of competing emphases. At its heart, there is the close examination of an empirical referent by way of a broader conceptual schema, or, as Jacques Hamel neatly puts it 'find[ing] the global in the local' (Hamel 1993: v). A referent can be an event, a process, a state of affairs or a set of behaviours; anything, provided it is indeed $a$ thing, standing in phenomenal distinction to the intellectual tools used to assay it. Von Wright makes the vital point that, methodologically, the relationship between description, explanation and theory is confounded. If we are talking about a temporal object like PAR we can add documentation to this list. The advantage of the case study is that it recognises this category bleed and can cope with it. So what is a 'case' exactly and what are the advantages of seeing PAR as 'cases'?

Michel Wievorka discusses the relationship between the social scientific 'case study' and the medical 'case history' and puts forward this definition:

For a 'case' to exist, we must be able to identify a characteristic unit, whose unity is given (at least initially) in concrete historical experiences. This unit must be observed, but it has no meaning in itself. It is significant only if an observer ... can refer it to an analytical category or theory... If you want to talk about a 'case' you need a means of interpreting it or placing it in a context... A case study cannot be merely empirical.

Regardless of the practical approach for studying it, a case is an opportunity for relating facts and concepts, reality and hypotheses. But ... it is [not], in itself, a concept. A case draws its unity not from the theoretical tools used to analyse it, but from the way it takes shape ... as a social and historical fact combining all sorts of elements into a set of comprising social roles, an institution, a social movement or a logic of action. By talking about a case, we propose bringing theory and practice together in a special way. (Wievorka 2009: 160)

One can see the appeal of this for PAR, and the message: that analytical value does not lie in the 'whole' which a case, empirically speaking, comprises, but in its constituting elements which have been subtracted from its phenomenal appearance and examined as elements via a hierarchy of concepts. This movement is in sharp contrast to the anabolic trajectory of an artwork, which is towards experiential totalisation. Whatever we see when sit down to a performance, it retains its framing as a performance until it is interrupted or over. For a performance to be analytically available the 'whole' must be 
attenuated, denatured. The case study can cope with this affront without letting it get out of hand: without collapsing into pure empirical observation on the one hand, or pure theoretical speculation on the other.

A case that is carved out of time and space must be both unique and representative. Its uniqueness will lie in its status as observable phenomenon, its representativeness in the claim to be an example of a certain kind of problem. 'The case under investigation, through the methodological qualities assigned to it ... becomes a sort of experimental prototype, to make an analogy with ... the ... natural sciences' says Hamel (1993: 37). To make an analogy with PAR and the rehearsal room too, choice of terrain is crucial. If researchers study selections whose features are ubiquitous it will be hard to frame them with definition or purpose. If they choose ones that are entirely original they will be hard to discuss in a broader way. But the case study can cope with limit instances: singularities that prompt a shift in the paradigm around them and common things assayed with conceptual looseness, at least initially. Most PAR are not going to change the face of modern theatre and most PAR scholars define their goals ahead of time. But the point is, the case study can tolerate extremes and by so doing avoid putting its analytical categories above the empirical field it is attempting to re-conceptualise. This means a welcome devalorisation of the 'research question'. Jennifer Platt observes of William Whyte's Street Corner Society that 'the research strategy followed can hardly be related to a clear initial hypothesis or research question, since there wasn't one, except perhaps of a very vague descriptive kind' (Platt 2009: 27). Street Corner Society is considered a qualitative research classic. Its analytical insights accrue later in the book, however, only when sufficient empirical matter has been examined. Wievorka's notion of shape or fit is the main thing here, how empirical referent and conceptual schema are brought together so as to be adequate to each other. In practice, this allows for considerable diversity of starting point and interpretive route. Provided case study researchers get somewhere, they have leeway about how to conduct their journey and where they eventually end up.

Related to this, and a function of it, the case study is flexible in respect to diachronic and synchronic perspectives. These perspectives are abrading ones. To view something as an unrepeatable historical event is not to view it as an effect of social structure. Yet they complement each other and to encompass both perspectives within the same approach is a bonus. 'Historical synthesis and sociological deconstruction are not alike, even though each may be applied to a single unit of study,' observes Wieviroka, 'A case study will, therefore, continuously oscillate between these two disciplines without necessarily being fully drawn to one or the other' (Wievorka 2009: 163). They meet in the middle, in the sense that an analytical axiom and a historical generalisation are much the same thing in the anti-positivist view. To say 'all performances have climaxes' for example, is to propose what could be either an analytical hypothesis or a generalisation about a range of instances under empirical examination. This fuzziness may not satisfy those looking for deductive modeling, with dependent and independent variables and statistically significant conclusions. But for case study methodology, operating in the warmer waters of inductive logic, near enough is good enough if it gets your closer to understanding the texture and truth of the real world (Johansson 2003).

If all this makes the case study sound loose both as a scholarly perspective and a set of techniques, there is an irreducible demand at its heart for the research goal not to be identified with cases per se. What stands to be explained (clarified) is not the case (in PAR, the performance), but a problem in the case, constructed as an object of study. This object, properly described via a 
hierarchy of concepts, presents as divisible, comparable and available to analytical extension (or historical generalisation). Description can and should try to capture all the relevant aspects of a case to ensure the construction of a broader intellectual vista. This means sweeping-in a wide range of evidence (eg. in PAR: statements of artistic intention, logs of creative process, documentation of final results, interviews, supplementary commentary, etc). Hamel calls this 'comprehensive description' or description 'in action' (39), which has echoes of Clifford Geertz's 'thick description', and for the same reason. Heterogeneity of research materials is licensed to ensure that desingularisation of a case - its re-conceptualisation as an object of study - pays due and careful attention to all aspects of its phenomenal appearance: its social (and aesthetic) features, its historical (and artistic) context, and most particularly, the terms and meanings imputed to it by those involved in its immediate situation. It is the last that the case study is particularly known for: its 'emic' sensitivities. This does not mean always using the language of the field to describe the field. But it does mean listening to it, and calibrating scholars' 'etic' categories after considering what is lost and gained thereby [6].

Since its revival in the 1960s, the case study has been used by a wide variety of researchers and is now a refined and reflexive tool of investigation. We can summarize the major requirements for its deployment in PAR:

- Case studies require a referent that has a good 'location' empirically and analytically. As Pierre Bourdieu remarks, 'a well-constructed single case is no longer singular' (cited in Hamel 35). The process of division involved in subtracting an object of study from an empirical referent requires a variety of potential problem areas be identifiable and applicable. Choice of object of study, rather than choice of research question, is the key initial step for case study researchers.

- Case studies require a comparative dimension to entrain analysis. While a paradigmatic 'case of one' is imaginable, every proponent of the case study stresses the need for comparison, both to establish good fit between a hierarchy of concepts and an object of study, and to filter the heterogeneous empirical material the approach allows (Becker 2008: xi). Comparisons can be made along a temporal axis (comparing one object to itself over time) or a structural one (comparing one object with other objects at a given moment in time) or both.

- Case studies require the utilization of a number of research methods, a 'triangulation' of data. This provides for the widest possible description of the relevant features of a referent, quantitative as well as qualitative, and de-valorises the research question, at least in the first instance.

Erving Goffman once facetiously remarked that the qualitative researcher really only has one question: 'what is it that's going on here?' (Goffman 1974: 8). This makes the case study good at picking up the finer features of referents that other more targeted methods leave out, and considering alternative forms of evidence.

- Case studies require a hierarchy of concepts, or theory, to organize and interpret their data. Sometimes this is confused with a hypothesis in the logico-deductive sense. But proponents of the case study mean something more straightforward. In the second edition of his influential book Art Worlds, Becker observes, 'we [do research] with the help of working ideas, what Herbert Blumer called 'sensitizing concepts'. The connection between theory and research... is that theories raise questions, suggest things to look at, point to what we don't know yet, and research answers questions but also makes us aware of things we hadn't thought of, which in turn suggest theoretical possibilities' (Becker 2008: xi) 
- Case studies can manage a mixture of 'etic' and 'emic' perspectives in their accounts, the language of analysis reflecting the categories and paradigms of academic scholarship, and the 'language of everyday life' reflecting the meaning-assignments of actors in a given situation. Case study research has the capacity to allow both languages scholarly attention, without reducing one to the other, or dismissing one or the other as 'anecdotal' or as 'abstract'. It is sensitive to dual orders of perception.

How does a selective array of methods turn into a Method with a capital M? As mentioned, case studies are known particularly for their close association with participant-observation. The stress should be on the first term: participation. Who can forget the image of Geertz running from the police after being part of a cheering crowd at a cockfight? Likewise, Whyte was a member of the community gangs he studied, and Becker trained as a photographer to write Artworlds. This participatory commitment is key for scholastic integrity in case study research for three reasons: i. it allows reality to be sifted for starting ideas in a way that no formula can provide; ii. it allows 'cases' to be selected from reality that can be then mined for their analytic insights; and iii. it allows researchers to validate their conclusions by bearing witness to the personal journey necessary in generating them. As Platt puts it: 'One way, and a rhetorically very effective way, of reaching a conclusion is to tell the story of how you arrived there yourself... This is a very different strategy from the 'scientific' one of concealing human agency in the production of findings, and starting with a hypothesis which has been confirmed' (Platt 2009: 29). Hamel quotes Zonabend to make the same point: 'the most rigorous objectivity is only possible through the most intrepid subjectivity' (cited in Hamel 1993: 43). The world is a world only because it is subjectively experienced. This is what turns data into life, variables into features. Case study methodology foundationally asserts that a researcher's subjectivity is central to their ability to conceive, execute and validate research. And if this is a bold point to make about research, it is a commonplace one to make about art. Here two orientations touch and an important conjunction arises whereby PAR can frame its body of work within the university system and make knowledge-claims in relation to it [7].

\section{Further Remarks}

In 2009, a Live Research seminar series was held at Edith Cowan University in response to "evidence that students doing practice-led research in the creative arts are variously intimated by, fearful or resentful of the need to prepare a ... written component to accompany their creative work' (Robson et al 2010: 188). The problem of the relationship between art and analysis lay at the heart of discussion. The anxiety of artist-researchers over the 'critical' component of their work related to a perception that the language of academic discourse was disconnected, overbearing, abstracting or dull. While the seminar was positive in tone overall, it put forward no practical suggestions about how the relationship was to be managed. Asserting the independent domain of art, speakers gave less consideration to the issue of conceptual transmissibility demanded by all forms of scholarly analysis. To be clear: we should acknowledge the ineffable features of art and their ever-disjunctive relationship to socially established epistemological figures; we can agree that exegetical writing invokes the power of its institutional setting. This fact will be keenly felt by artist-researchers offering analysis of their own creative work. Nevertheless, the problem cannot be left as a matter of 'pragmatic choice' (197), as the seminar suggests. Some parameters must be agreed if the area is to 
be an enduring addition to university scholarship. The case study approach can facilitate this, and in an art-sensitive register.

To return to a persistent problem: to what extent should the performance component of PAR projects be subject to assessments of their 'excellence'? At the 2012 Australasian Drama Studies conference (ADSA) a list of national peer assessors was again proposed. What criteria would they apply to individual projects? Will the academy promulgate its own version of 'standards' or will it transship those of the profession, as the ERA program seems inclined to do? Case study methodology can make a contribution here too. For its proponents, the phenomenal appearance of a case, while important, is the gateway and not the end point of a research project. The performance is not the target, but the problem the performance is construed as representing. The presumed lack of identity between case and object of study is an enabling one, creating an 'explanatory gap' via which the scholarly imagination can deploy. In using the case study approach, artists must split their subjectivity, see their artwork not only as creatively singular but as an example of a type. Any excellence imputed to the artwork resides chiefly in its ability to produce analytical vistas for investigation, not with any aesthetic criteria invoked additional to this task. This de-emphasises the artistic assessment of PAR. It does not void it, but it shifts the focus from measuring a controversial, and difficult to evidence, 'excellence' to a necessary and demonstrable 'competence'. A PAR artwork must be adequate to the analysis it is conjoined to, experientially strong enough as a case to seed objects of study.

The case study also points away from the passive documentation of PAR and towards the task of active description. The current debate places a great deal of importance on documentation. At ADSA, Haseman laid out the lengths Queensland University of Technology currently go to document the creative arts projects that take place within its institutional orbit. Such an approach, apart from raising the issue of who will read such voluminous material, runs the risk in Hamel's words of being 'a restatement of information that has been collected and arranged by the written word to give it a systematic appearance' (48). Forcing new analytical insights into the open, for case study researchers, is a job for description. Indeed, it is the job for description. As Hamel also adds, 'at its best, description provides an explanation' (39). The return of the J form - although in more rigorous application than originally envisioned.

To conclude with a brief example of how case study methodology might be applied to a potential PAR project. As We Forgive by Tom Holloway is a play I directed in 2013. This work was developed over a three-year period by a creative team that included a photographer and a classical composer, and was staged in Hobart, for the Ten Days on the Island Festival in March. It is a monopolydrama (drama in which a single actor plays a number of different characters) in three sections, stylistically and thematically linked. Each part is based on a moral inversion, taking an apparently negative value - vengeance, hate, lack of forgiveness - and exploring its positive benefits. How could this project be considered as a case in relation to an ecology of problem types? How can the singular being of a unique live performance artwork, with all its attendant subjectivities and ineffabilities, be framed as an object of common knowledge commanding consensus from both academic scholars and participating artists?

Case study methodology does not begin with a hero question - what is a drama of forgiveness? How does live performance freight moral reflection? - but with the identification of potential categories of analysis that can be used to construct a comparative vista. For example: 
In relation to form:

- monopolydramas

- dramas of proposition/extended argument

- dramas of reported action

- dramas of overt schematization

In relation to theme:

- dramas of intellectual inversion

- dramas of moral confrontation

- dramas of proposition/extended argument

- dramas of current engagement

In relation to performance aura:

- confessional performances

- visually minimalist performances (reported action)

- performances soliciting complicity

- narrative monologuing

In relation to itself:

- conception of the artwork

- different phases of the development of the artwork

- the 'artworld' of the artwork

- execution of the artwork

Existentially-viewed:

- artworks of moral ineffability

- artworks of serious moral intent

- artworks of threshold themes/images

- artworks containing complex ideational structures

Contextually-viewed:

- the plays of Tom Holloway

- the drama of contemporary Tasmania

- performance projects happening in the wake of the collapse of Zootango Theatre

- artworks exploring a 'regional' Australian sensibility

Each of these problem types proposes a different way of de-singularising the experience of As We Forgive and seeing it in a representative light. Note that the aperture of research can be controlled, depending on whether the desired comparative vista is 'drama', 'performance', 'artwork' or some other directly contextual concern. The 'excellence' of As We Forgive as a performance experience would be less important than its role in opening up potential research pathways to study this concern. It does not have to be 'good' but 'good enough'. From this opening up, a question, probably a series of questions would arise, necessarily loose-fit. The case study researcher would be concerned with the balance between 'etic' and 'emic' perspectives and have a clear understanding of how subjective experience can validate general claims. Their research would involve a triangulation of methods and an openness to different kinds of evidence. The critical tasks would relate to description, not documentation. It is the job of well-accomplished description to illuminate the explanatory pathway between a unique artwork and an object of study, identified for analytical purposes. 
One last point about case study methodology: it is readily accessible. For all the sophistication of its values and concepts, it discusses the world in natural language, deploying a modest array of specialized terms. For PLR, subject to a seemingly never-ending torrent of neologisms, this simplicity must surely have its attractions. It will certainly appeal to artists in the field considering a return to university to complete creative MAs or PhDs. Unlike Haseman and Mafe, I do not regard the profession as typically conservative; far from it. The performing arts sector is more complex and varied today than at any other time in our history. If the tertiary sector is to develop a fruitful relationship with the sector, it will need to consider not only what constitutes knowledge in a scholastic sense, but what kinds of knowledge production best suit practicing artists. Case study methodology meets this concern well.

The methods of active description such that 'cases' are converted to 'objects of study' by way of 1) adequate empirical investigation, and 2) select analytical concepts that yield high explanatory return, are of great use to the PAR area, I would suggest. The case study can assist in the framing of individual projects by casting them as problems exemplifying a general area. This allows artistresearchers to attend not just to the singular features of their artworks, but to the shared figures of knowledge acknowledged by the scholarly community they have elected to join.

\section{Notes}

[1] Measuring the value of creative work (or cognates such as 'quality' and 'excellence') is a major methodological problem for any type of inquiry. It is the subject of considerable attention from cultural economists, particularly David Throsby, who has noted: 'Cultural value ... is multi-dimensional, unstable, contested, lacks a common unit of account and may contain elements that cannot be easily expressed according to any quantitative or qualitative scale. The characteristics of cultural goods which give rise to their cultural value might include their aesthetic properties, their spiritual significance, their role as purveyors of symbolic meaning, their historic importance, their significance in influencing artistic trends, their authenticity, their integrity, their uniqueness and so on' (Throsby 2003: 279). Given the intractability of the cultural value problem it is unlikely universities will be able to generate a standardized assessment metric for it. This article is underscored by a more fluid, multi-faceted understanding of 'excellence' - ie. as something that exists but which cannot be unilaterally defined. return to text

[2] See Hamel with Dufour and Fortin, 'Conflicts of Methods' in Hamel 1993: 18-27 return to text

[3] See R Rorty Philosophy and the Mirror of Nature (1979). Following in the footsteps of John Dewey, Rorty is concerned to reduce science's claims to privileged objective knowledge and put them on a par with other approaches contributing to the well-being of the community (being 'edifying'). return to text

[4] My communication with La Trobe University took the form of a general memo on 'Creative Arts and the Research Quantum' and a more specific one on 'Type of Research Activity Undertaken in the Theatre and Dama Program', submitted, together with a draft 'J Form', in letter to Professor Fred Smith, Dean of Humanities, on 29 April 1999. return to text

[5] The outcomes of this ARC project, which involved three theatre artists and three academics, culminated in a presentation of a performance work and a series of related papers at the Biennial Australasian Shakespeare Conference in 2002 (Meyrick 2002), followed by a public season of the work alone. return to text

[6] This leaves room for bold re-conceptualizations. When Geertz leaps to an abstract formularisation of 'deep play' in Notes on a Balinese Cockfight (Geertz 1971: 439), or Whyte demonstrates the unconscious dynamics of social mobility in an American slum (Whyte 1993: 94-98), even Levi-Strauss - not a proponent of 'common place evidence' - may be satisfied that 'the concealed internal logic of ... reality' (cited in Hamel 1993: 30) has been articulated. 
There are no rules for these jumps, however. Geertz and Whyte offer their global insights when they judge they have sufficient empirical basis for them, and not according to a given figure of claim and proof. return to text

[7] Underlying this is the interesting question: is the case study an approach or a methodology? This issue could descend into a squabble about terms and definitions but it has a hard centre to it. The case study uses different tools to describe and explain its objects of study. Therefore, it would seem to be an approach that uses different methods to achieve its sundry ends. But its proponents go further and argue that these methods, combined, or in Chicago School parlance, 'triangulated', constitute a careful, systematic and forceful reconstruction of part of reality adequate to the whole of reality. Thus the case study is a method in its own right. I make this point because the role and perspective of the researcher is key to this promotion. Unlike functionalist and statistical approaches to social phenomenon, researcher's thoughts and feelings are not viewed as contaminants in the knowledge-accruing process, but are central to that accrual. This means the case study is uniquely placed to manage the personal identification between researcher and artwork that is a feature of PAR, to provide the area with epistemological coordinates. return to text

\section{Works Cited}

Barrett, E \& B Bolt 2007 Practice as Research: Approaches to Creative Inquiry, IB Tauris, London return to text

Becker, H 2008 [1982] Art Worlds (second edition), University of California Press, Berkley CA return to text

Becker, H 2009 [1992] 'Cases, Causes, Conjunctions, Stories and Imagery', in C Ragin \& H Becker (eds) What is a Case? Exploring the Foundations of Social Inquiry, Cambridge University Press, Cambridge: 205-216 return to text

Becker, H 2011 'The Chicago School, So-called', Howie's home page: http://home.earthlink.net/ hsbecker/articles/chicagohtml (accessed 25 January 2011) return to text

Deegan, M 2001 'The Chicago School of Ethnography', in P Atkinson, A Coffey et al (eds) Handbook of Ethnography, Sage Publications, Thousand Oaks CA: 11-25 return to text

Geertz, C 1971 'Notes on a Balinese Cockfight', The Interpretation of Culture: Selected Essays, Basic Books, New York: 412-53 return to text

Gillies, M 1997 'The Creative Arts and Research', in A Richards \& Angela O’Brien (eds) Proceedings of the National Symposium on Research in the Performing Arts, May 15-18, 1997, University of Melbourne, Parkville Vic: 26-32 return to text

Goffman, E 1974, Frame Analysis: An Essay on the Organisation of Experience, Harvard University Press, Cambridge MA return to text

Hamel, J with S Dufour \& D Fortin 1993, Case Study Methods, Sage Publications, Thousand Oaks CA return to text

Haseman, B 2006 'A Manifesto for Performative Research', QUT ePrints: http://eprints.qut.edu.au/3999/ (accessed 8 January 2013) return to text

Haseman, B \& D Mafe 2009 'Acquiring Know-How: Research Training for Practice-Led Researchers', in H Smith \& RT Dean (eds) Practice-led Research, Research-led Practice in the Creative Arts, Edinburgh University Press, Edinburgh: 211-228 return to text

Hecq, D \& R Banagan 2010 'Practice, research and their phantom limb', TEXT 14, 1 (April): http://researchbank.swinburne.edu.au/vital/access/manager/Repository/swin:17286 (accessed 8 January 2013) return to text

Johansson, R 2003 'Case Study Methodology', Keynote speech, Methodologies in Housing Research Conference, Stockholm, 22-24 September 2003:

http://wwwscribdcom/doc/108918905/Case-Study-Methodology (accessed 22 October 2012) return to text 
Lutters, W \& M Ackerman 1996 'Social Relations in Complex Environments: An Introduction to the Chicago School of Sociology' UCI-ICS Social Worlds Lab \#96-1

http://userpages.umbc.edu/ lutters/pubs/1996_SWLNote96-1_Lutters,Ackerman.pdf (accessed 14 July 2014) return to text

Meyrick, J 2002 'The Othello Exploration: A Performance As Research Project', Seventh Biennial Australian and New Zealand Shakespeare Conference (unpublished conference paper) return to text

Platt, J 2009 [1992] 'Cases of cases ... of cases', in C Ragin \& H Becker (eds) What is a Case? Exploring the Foundations of Social Inquiry, Cambridge University Press, Cambridge: 21-52 return to text

Richards, A \& Y Prior 1997 'Evaluating Performance as Research - the Assessor's Perspective', Double Dialogues: A Conference with a Difference, November, Deakin University, Melbourne: 54-58 return to text

Robson, J, D Brady \& L Hopkins 2010 'From Practice to the Page: Multi-Disciplinary Understandings of the Written Component of Practice-Led Studies', Australasian Drama Studies 57 (October): 188-199 return to text

Rorty, R 1979 Philosophy and the Mirror of Nature, Princeton University Press, Princeton return to text

Smith, H \& RT Dean 2009 Practice-led Research, Research-led Practice in the Creative Arts, Edinburgh University Press, Edinburgh return to text

Stake, R 2005 'Case Studies', in N Denizen \& Y Lincoln (eds) Handbook of Qualitative Research (2nd edition), Sage Publications, Newbury Park, CA: 435-454 return to text

Strand, D 1998 'Developing Research, Scholarship and Creative Works Categories for the Creative Arts', in A Richards \& A O'Brien (eds) Proceedings of the National Symposium on Research in the Performing Arts, May 15-18, 1997, University of Melbourne, Parkville Vic: 81-97 return to text

Throsby, D 2003 'Determining the Value of Cultural Goods: How Much (or How Little) Does Contingency Valuation Tell Us?' Journal of Cultural Economics 27: 275-285 return to text

Von Wright, G 1971 Explanation and Understanding, Cornell University Press, Ithaca NY return to text

Wievorka, M 2009 [1992] 'Case Studies: History or Sociology?', in C Ragin \& H Becker (eds) What is a Case? Exploring the Foundations of Social Inquiry, Cambridge University Press, Cambridge: $159-172$ return to text

Whyte, W 1993 [1943] Street Corner Society (4th edition), University of Chicago Press, Chicago return to text

Wissler, R 1998, 'Benchmarks, Interpretation and Peers: Judging Performance as Research Publication', in A Richards \& A O'Brien (eds) Proceedings of the National Symposium on Research in the Performing Arts, May 15-18, 1997, University of Melbourne, Parkville Vic: 58-65 return to text

Yin, RK 1989 Case Study Research: Design and Method (revised edition), Sage Publications, Newbury Park CA return to text

Julian Meyrick is Strategic_Professor of Creative Arts at Flinders University, Artistic Counsel for the State Theatre Company of South Australia and an Honorary Associate at La Trobe University. He is a leading developer of new Australian drama and the director of many award-winning theatre productions. Currently he is a member of a Flinders University research team studying the problem of cultural value and related assessment methodologies. 


\section{TEXT}

Vol 18 No 2 October 2014

http://www.textjournal.com.au

General Editor: Nigel Krauth. Editors: Kevin Brophy, Enza Gandolfo \&

Linda Weste

text@textjournal.com.au 